\title{
Impact of a Respiratory Therapy Assess-and-Treat Protocol on Adult Cardiothoracic ICU Readmissions
}

\author{
Robert T Dailey MHA RRT-ACCS, Thomas Malinowski MSc RRT FAARC, \\ Mitchel Baugher RRT, and Daniel D Rowley MSc RRT-ACCS RRT-NPS RPFT FAARC
}

\begin{abstract}
BACKGROUND: The purpose of this retrospective medical record review was to report on recidivism to the ICU among adult postoperative cardiac and thoracic patients managed with a respiratory therapy assess-and-treat (RTAT) protocol. Our primary null hypothesis was that there would be no difference in all-cause unexpected readmissions and escalations between the RTAT group and the physician-ordered respiratory care group. Our secondary null hypothesis was that there would be no difference in primary respiratory-related readmissions, ICU length of stay, or hospital length of stay. METHODS: We reviewed 1,400 medical records of cardiac and thoracic postoperative subjects between January 2015 and October 2016. The RTAT is driven by a standardized patient assessment tool, which is completed by a registered respiratory therapist. The tool develops a respiratory severity score for each patient and directs interventions for bronchial hygiene, aerosol therapy, and lung inflation therapy based on an algorithm. The protocol period commenced on December 1, 2015, and continued through October 2016. Data relative to unplanned admissions to the ICU for all causes as well as respiratory-related causes were evaluated. RESULTS: There was a statistically significant difference in the all-cause unplanned ICU admission rate between the RTAT $(5.8 \%$ [95\% CI 4.3-7.9]) and the physician-ordered respiratory care $(8.8 \%$ [95\% CI 6.9-11.1]) groups $(P=.034)$. There was no statistically significant difference in respiratory-related unplanned ICU admissions with RTAT (36\% [95\% CI 22.7-51.6]) compared with the physician-ordered respiratory care $(53 \%$ [95\% CI 41.1-64.8]) group $(P=.09)$. The RTAT protocol group spent $1 \mathrm{~d}$ less in the ICU $(P<.001)$ and in the hospital $(P<.001)$. CONCLUSIONS: RTAT protocol implementation demonstrated a statistically significant reduction in all-cause ICU readmissions. The reduction in respiratory-related ICU readmissions did not reach statistical significance. Key words: ICU readmission; patient readmissions; respiratory care; respiratory therapy; postoperative care; length of stay; cardiovascular; cardiothoracic; surgery; protocol. [Respir Care 2017;62(5):517-523. (C) 2017 Daedalus Enterprises]
\end{abstract}

\section{Introduction}

Respiratory therapy assess-and-treat (RTAT) protocols have been shown to be effective in the alignment of therapeutic interventions to patient need. Effectively managed

\footnotetext{
The authors are affiliated with the Department of Pulmonary Diagnostics and Respiratory Therapy Services, University of Virginia Medical Center, Charlottesville, Virginia.
}

Mr Dailey presented a version of this paper as an Editors' Choice abstract at AARC Congress 2016, held October 15-18, 2016, in San Antonio, Texas.

The authors have disclosed no conflicts of interest.

Correspondence: Robert T Dailey MHA RRT-ACCS, University of Virginia Medical Center Department of Pulmonary Diagnostics and respiratory therapy protocols have been shown to reduce the incidence of unnecessary care, ICU length of stay, and length of hospitalization. ${ }^{1}$ RTAT protocols have also been reported to reduce medication and total hospital costs as well. ${ }^{2,3}$ When combined, these successful applications demonstrate that RTAT protocols can be effective in improving performance and quality indicators of departmental and hospital care. ${ }^{4-6}$

A suggested target for performance improvement in ICUs is demonstrating a reduction in the rate of ICU readmissions (bounce-backs) and unexpected ICU admissions (bounce-

Respiratory Therapy Services, P.O. Box 800686, Charlottesville, VA 22908-0686. E-mail: rtd6b@virginia.edu.

DOI: $10.4187 /$ respcare. 05269 
ups). ICU readmissions and unexpected ICU admissions are linked to longer critical care stays, longer hospital stays, greater in-hospital mortality, greater 1-y mortality, and higher total hospital costs. ${ }^{7}$ Patients with more severe and complex illnesses have been reported to be more likely to be readmitted. ${ }^{8}$ Nationwide, readmissions to the ICU range from 1.2 to $14.5 \%$ with a median value of $5.9 \%$ across various bed-size and acuity level units. ${ }^{8}$

\section{See the Related Editorial on Page 636}

Little has been reported on the impact of RTAT protocols on intensive care readmissions and unexpected ICU admissions. Readmissions after cardiac surgery range from 2 to $9 \%$ and are associated with a 5-7-fold increase in mortality. ${ }^{7-9}$ Respiratory-related complications have been identified as a principle driver of bounce-backs and bounceups among cardiac and thoracic surgery patients. ${ }^{7}$ Consequently, the application of an RTAT may be effective in reducing respiratory-related bounce-backs and bounce-ups in the adult cardiothoracic postoperative population.

We developed an RTAT protocol and then applied the protocol to a population of adult cardiothoracic postoperative patients. This RTAT protocol included therapeutic interventions for lung expansion therapy, bronchial hygiene, and aerosol therapy. We developed key quantitative and qualitative outcome measures to assess protocol effectiveness. The purpose of this institutional review board-approved retrospective medical record review was to report on bounce-backs and bounce-ups to the ICU among adult postoperative cardiothoracic subjects managed with an RTAT and to compare those results with historical performance.

\section{Methods}

\section{Study Design and Subjects}

We performed this single-center retrospective analysis of prospectively recorded data related to the application of an RTAT protocol within the thoracic-cardiovascular postoperative ICU, acute care ward, and thoracic intermediate care units, also known as the Heart Center, at the University of Virginia Medical Center between November 2015 and October 2016. The University of Virginia Medical Center is a 585-bed academic medical center located in Charlottesville, Virginia. The Heart Center consists of 2 postoperative ICUs totaling 20 beds, an intermediate care area of 12 beds, and an acute care ward encompassing an additional 28 beds. Registered respiratory therapists are used exclusively for the provision of respiratory care services at the University of Virginia Medical Center. This study was exempted from full committee review and approved by the University of Virginia human subject re-

\section{QUICK LOOK}

\section{Current knowledge}

Academic medical centers tend to experience a greater rate of unexpected admissions and readmissions to the ICU. Respiratory compromise has been shown to be a primary driver of this phenomenon. Respiratory therapist (RT)-managed clinical protocols have demonstrated value in the care process, both inside and outside the ICU. The exact impact these types of protocols have on reducing ICU admissions and readmissions is unclear.

\section{What this paper contributes to our knowledge}

We found that an RRT-managed assess-and-treat protocol can reduce unexpected admissions and readmissions to the ICU within an adult cardiothoracic postoperative cohort. Implementing an RT-managed assessand-treat protocol among a population of adult postoperative cardiothoracic subjects showed a reduction in bounce-backs and bounce-ups to the ICU that was statistically significant for all-cause readmissions but not statistically significant for primary respiratoryrelated causes. This work also demonstrated a reduction in ICU length of stay as well as hospital length of stay.

search institutional review board as a quality improvement project before medical record review and data collection.

We reviewed 1,400 medical records of adult cardiac and thoracic postoperative subjects treated at the University of Virginia Medical Center from January 1, 2015, through October 20, 2016. The RTAT protocol was implemented in mid-November 2015, with 2 weeks of "onboarding" to allow for education and training. January 2015 through November 15, 2015, served as the control period during which no protocol was applied. The control group (physician-ordered respiratory care group) was made up of 730 subjects who were admitted to the thoracic-cardiovascular postoperative ICU from either the postoperative acute care ward or the thoracic intermediate care unit. The subjects included patients who were recently discharged from the thoracic-cardiovascular postoperative ICU to the acute care thoracic intermediate care unit or who were directly admitted from the operating room to this area. All subjects were adult cardiothoracic postoperative patients.

The protocol period commenced on December 1, 2015, and continued through October 20,2016. The study group (RTAT) consisted of 670 subjects meeting similar surgical criteria as the control group. For the purposes of this project, ICU readmission was defined as return or escalation to the thoracic-cardiovascular postoperative ICU before hospital discharge. Primary respiratory-related readmission was defined as readmission associated with complications 


\section{Respiratory Therapy Assess-AND-Treat Protocol}

\begin{tabular}{|c|c|c|c|c|}
\hline \begin{tabular}{|l} 
Clinical Findings \\
Disease \\
(Bronchial Hygiene)
\end{tabular} & $\begin{array}{l}\text { None }(0) \\
\square \text { No pulmonary } \\
\text { history }\end{array}$ & $\begin{array}{l}\text { Mild }(1 \mathrm{pt}) \\
\text { COPD, acute or } \\
\text { traumatic lung injury, } \\
\text { neuromuscular }\end{array}$ & $\begin{array}{l}\text { Moderate (2 pts) } \\
\square \text { Non-CF bronchiectasis, } \\
\text { thoracic surgery }\end{array}$ & $\frac{\text { Severe }(3 \mathrm{pts})}{\square \text { Cystic fibrosis }}$ \\
\hline $\begin{array}{l}\text { Cough Effectiveness } \\
\text { (Bronchial Hygiene) }\end{array}$ & $\square$ Strong & a Weak & $\square$ Requires suctioning & \\
\hline $\begin{array}{l}\text { Air Movements/Breath } \\
\text { Sounds } \\
\text { (Aerosol, Bronchial Hygiene) }\end{array}$ & $\square$ Normal & $\begin{array}{l}\text { Expiratory wheeze, } \\
\text { clears with cough }\end{array}$ & $\begin{array}{l}\text { Inspiratory/expiratory } \\
\text { wheeze, not clearing } \\
\text { with cough }\end{array}$ & $\begin{array}{l}\text { J Severe wheeze, } \\
\text { diminished/absent }\end{array}$ \\
\hline $\begin{array}{l}\text { Respiratory Pattern/WOB } \\
\text { (Aerosol) }\end{array}$ & $\begin{array}{l}\square \text { Regular pattern, } \\
\text { depth,frequency }\end{array}$ & $\begin{array}{l}\text { Altered frequency, } \\
\text { dyspnea on exertion }\end{array}$ & $\begin{array}{l}\text { Dyspnea at rest, } \\
\text { accessory muscle use, } \\
\text { prolonged expiratory, } \\
\text { retractions }\end{array}$ & $\begin{array}{l}\text { J Severe dyspnea pursed } \\
\text { lipped breathing, significant } \\
\text { accessory muscle use, } \\
\text { paradoxical breathing }\end{array}$ \\
\hline $\begin{array}{l}\text { Pulmonary Impairment } \\
\text { (Aerosol, Lung Expansion) }\end{array}$ & $\begin{array}{l}\square(-) \text { History/ } \\
\text { (-) Smoking }\end{array}$ & $\begin{array}{l}\text { Smoking history, and/or } \\
\text { history of lung disease }\end{array}$ & $\begin{array}{l}\text { D Pulmonary history with } \\
\text { 1-2 exacerbations/y }\end{array}$ & $\begin{array}{l}\square \text { Admission for pulmonary } \\
\text { exacerbation within y }\end{array}$ \\
\hline $\begin{array}{l}\text { Surgical/Neuromuscular } \\
\text { Status } \\
\text { (Lung Expansion) }\end{array}$ & $\begin{array}{l}\square \text { None, general } \\
\text { surgery }\end{array}$ & $\square$ Lower abdominal & $\begin{array}{l}\text { Thoracic injury, upper } \\
\text { abdominal, neuromuscular } \\
\text { disorder with diaphragm } \\
\text { impairment }\end{array}$ & Thoracic surgery \\
\hline $\begin{array}{l}\text { Chest x-ray } \\
\text { (Lung Expansion) }\end{array}$ & $\square$ Clear & $\begin{array}{l}\text { Chronic changes or } \\
\text { x-ray pending }\end{array}$ & $\begin{array}{l}\text { Infiltrated, atelectasis, } \\
\text { pleural effusions in one } \\
\text { lung quadrant }\end{array}$ & $\begin{array}{l}\square \text { Infiltrated, atelectasis } \\
\geq 2 \text { quadrant }\end{array}$ \\
\hline $\begin{array}{l}\text { Activity Level } \\
\text { (Lung Expansion, } \\
\text { Bronchial Hygiene) }\end{array}$ & $\begin{array}{l}\square \text { Ambulatory with or } \\
\text { or without assistance }\end{array}$ & $\begin{array}{l}\text { I Non-ambulatory, able } \\
\text { to position self }\end{array}$ & $\begin{array}{l}\text { Non-ambulatory, unable } \\
\text { to position self }\end{array}$ & \\
\hline $\begin{array}{l}\text { Oxygen Level } \\
\text { (Lung Expansion) }\end{array}$ & $\square$ Room air & $\begin{array}{l}\mathrm{U} U \mathrm{p} \text { to } 40 \% \text { to maintain } \\
\mathrm{S}_{\mathrm{pO}_{2}} \% \text { at baseline, } \\
\text { or } \geq 92 \%\end{array}$ & $\begin{array}{l}\square>40 \% \text { to maintain } \\
\mathrm{S}_{\mathrm{pO}_{2}} \% \text { at baseline, } \\
\text { or } \geq 92 \%\end{array}$ & \\
\hline
\end{tabular}

Fig. 1. Clinical severity scoring tool. CF = cystic fibrosis.

of airway secretion retention, acute hypercarbic respiratory failure resulting in the need for noninvasive or invasive ventilatory support, or acute hypoxemic respiratory failure $\left(\mathrm{S}_{\mathrm{pO}_{2}}<90 \%\right)$. The primary outcome of this project was to examine unexpected readmissions and escalations to the ICU. Our primary null hypothesis was that there would be no difference in all-cause unexpected readmissions and escalations between the RTAT group and the physician-ordered respiratory care group. Secondary outcomes included primary respiratory-related readmissions, ICU stay, and hospital stay. Our secondary null hypothesis was that there would be no difference in primary respiratory-related readmissions.

The RTAT protocol is driven by a standardized patient assessment tool, which is completed by a registered respiratory therapist in the role of clinical assessor (Fig. 1). The tool develops an individualized respiratory severity score for each patient and directs interventions for bronchial hygiene, aerosol therapy, and lung inflation therapy based on an algorithm (Fig. 2). The protocol was integrated as a part of the computerized physician order entry function of the electronic medical record. All cardiac and thoracic postoperative patients transferred from the thoracic-cardiovascular postoperative ICU to the thoracic-cardiovascular acute care/thoracic intermediate care unit ward as well as thoracic postoperative patients admitted directly from the operating room to this ward were placed on the protocol. A protocol-based assessment was then initiated by the clinical assessor. The patient assessment scoring tool and flow sheet were built into the electronic medical record for documentation of evaluations related to initiation of the protocol and ongoing management of protocol patients. Patient assessment utilized a 3-phase approach that included evaluation of patient indications for aerosol therapy, bronchial hygiene, and lung inflation therapy. Orders for medication and therapeutic interventions were based on severity scoring at the level of minimal (0-2), mild (3-4), moderate $(5-6)$, and severe $(\geq 7)$. Patients were then reevaluated every $12-24 \mathrm{~h}$ according to severity scores and indices. Respiratory therapy orders were modified by the clinical assessor according to the results and scoring tool.

\section{Data Collection and Analysis}

A retrospective analysis was undertaken to determine the number of subjects who bounced up or bounced back to the thoracic-cardiovascular postoperative ICU from the thoracic-cardiovascular acute care and thoracic intermediate care units within the physician-ordered respiratory care group period (control). Subject records were reviewed for the time period spanning from January 2015 through November 2015. These data were then compared with data collected from cardiothoracic postoperative subjects managed after implementation of the RTAT protocol (December 2015 through October 2016). Subjects were stratified among 9 surgical intervention types, including aortic/vascular, coronary artery bypass graft, esophagectomy, heart transplant/left-ventricular assist device, lung/chest, lung transplant, ventricular assist device, valve, and other. Data collected for comparison purposes between the RTAT and 


\section{Respiratory Therapy Assess-And-Treat Protocol}

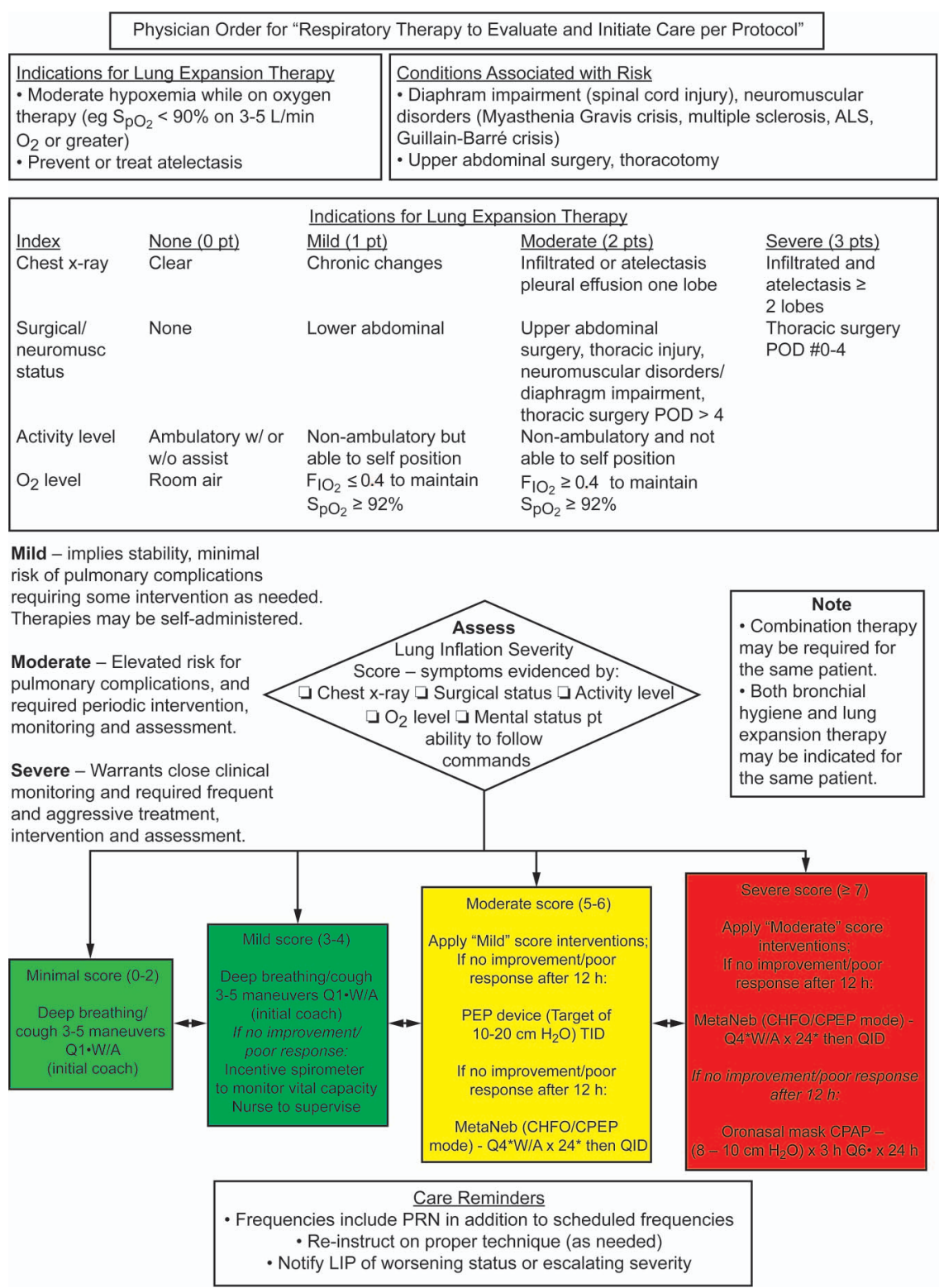

Fig. 2. Treatment algorithm. ALS = amyotrophic lateral sclerosis, $\mathrm{POD}=$ postoperative day, $\mathrm{PEP}=$ positive expiratory pressure, $\mathrm{CHFO}=$ continuous high-frequency oscillation, PRN = when necessary, LIP = licensed independent practitioner, Q1 = every one hour, Q4 = every four hours, Q6 = every six hours, W/A = while awake, TID = three times per day, QID = four times per day, CPEP = continuous positive expiratory pressure.

physician-ordered respiratory care groups included subject demographics, surgical diagnosis, case mix index, ICU length of stay, and hospital length of stay. ICU readmission and whether the primary cause of readmission was respiratory-related were recorded after reviewing the respective electronic medical records. Continuous variables were reported as mean \pm SD or median (interquartile range) based on the Shapiro-Wilk test of normality of distribution. Categorical variables were reported as $n(\%)$. Continuous data were analyzed with an independent-samples $t$ test or Mann-Whitney U test, whereas categorical variables were analyzed using chi-square of independence test or Fisher ex- act test, as appropriate. $P$ (2-tailed) $\leq .05$ was considered statistically significant. Statistical analysis was performed using SPSS 23 for Windows (IBM Corp, Armonk, New York).

\section{Results}

Data analysis included 1,400 subjects between the RTAT $(n=670)$ and physician-ordered respiratory care $(n=730)$ groups. Mean age $(64 \pm 13.4 \mathrm{y})$ was similar between groups $(P=.69)$. Males represented $66 \%$ of the study population. The RTAT protocol group spent $1 \mathrm{~d}$ less in the ICU and in the hospital compared with the physician-ordered respiratory care 


\section{Respiratory Therapy Assess-AND-Treat Protocol}

Table 1. Subject Characteristics

\begin{tabular}{|c|c|c|c|}
\hline Characteristics & $\begin{array}{l}\text { Physician-Ordered } \\
\text { Respiratory Care } \\
\text { (Control Group) } \\
(n=730)\end{array}$ & $\begin{array}{c}\text { Respiratory Therapy } \\
\text { Assess-and-Treat Protocol } \\
\text { (Experimental Group) } \\
(n=670)\end{array}$ & $P$ \\
\hline Age, mean \pm SD y & $64 \pm 13.4$ & $64 \pm 14.3$ & .69 \\
\hline Male sex, $n(\%)$ & $481(66)$ & $427(64)$ & .40 \\
\hline CMI, median (IQR) & $5.7(4.6-7.7)$ & $5.1(3.7-6.2)$ & $<.001 *$ \\
\hline ICU LOS, median (IQR) d & $3.0(2-6)$ & $2(1-4)$ & $<.001 *$ \\
\hline Hospital LOS, median (IQR) d & $8(6-14)$ & $7(5-11)$ & $<.001 *$ \\
\hline \multicolumn{4}{|l|}{ Surgical procedure, $n(\%)$} \\
\hline Aortic/vascular & $46(6)$ & $20(3)$ & $.003 *$ \\
\hline CABG & $215(30)$ & $223(33)$ & .12 \\
\hline Esophagectomy & $28(4)$ & $66(10)$ & $<.001 *$ \\
\hline Heart transplant/LVAD & $32(4)$ & $5(<1)$ & $<.001 *$ \\
\hline Lung/chest & $39(5)$ & $84(13)$ & $<.001 *$ \\
\hline Lung transplant & $10(1)$ & $16(2)$ & .16 \\
\hline VAD & $6(<1)$ & $2(<1)$ & .35 \\
\hline Valve & $334(46)$ & $236(35)$ & $<.001^{*}$ \\
\hline Other & $20(3)$ & $18(3)$ & .95 \\
\hline $\begin{array}{l}* P(2 \text {-tailed })<.01 \text { is considered statistical } \\
\text { CMI }=\text { case mix index } \\
\text { IQR }=\text { interquartile range } \\
\text { LOS }=\text { length of stay } \\
\text { CABG }=\text { coronary artery bypass graft } \\
\text { LVAD }=\text { left-ventricular assist device } \\
\text { VAD }=\text { ventricular assist device }\end{array}$ & & & \\
\hline
\end{tabular}

Table 2. All-Cause Cardiothoracic ICU Readmissions

\begin{tabular}{|c|c|c|c|}
\hline Respiratory Care Treatment Group & $\begin{array}{c}\text { All-Cause } \\
\text { Cardiothoracic ICU } \\
\text { Readmission, } n(\%)\end{array}$ & $\begin{array}{l}\text { No Cardiothoracic ICU } \\
\text { Readmission, } n(\%)\end{array}$ & Total, $n$ \\
\hline Physician-ordered respiratory care (control) & $64(8.8)$ & $666(91.2)$ & 730 \\
\hline Respiratory therapy assess-and-treat protocol (experiment) & $39(5.8)^{*}$ & $631(94.2)$ & 670 \\
\hline Total & 103 & 1,297 & 1,400 \\
\hline
\end{tabular}

group, whereas the physician-ordered respiratory care group had a higher case mix index $(P<.001)$ (Table 1$)$. Chi-square of independence was conducted between respiratory care treatment groups and cardiothoracic ICU readmission status. Allcause cardiothoracic ICU readmission was lower in the RTAT protocol group (5.8\% [95\% CI 4.3-7.9]) compared with the physician-ordered respiratory care group (8.8\% [95\% CI 6.911.1]), $P=.034$. Our RTAT protocol resulted in an absolute risk reduction of $2.9 \%(95 \%$ CI $0.2-5.7)$ and odds ratio $=1.6$ (95\% CI 1.0-2.3) (Table 2). Three percent of ICU readmissions in the combined groups $(N=1,400)$ were primarily respiratory-related $(n=48)$. Respiratory-related cardiothoracic ICU readmission was lower in the RTAT protocol group ( $n=14 ; 36 \%$ [95\% CI 22.7-51.6]) compared with the physician-ordered respiratory care group $(n=34 ; 53 \%$ [95\% CI 41.1-64.8]), but the difference was not statisti- cally significant $(P=.09)$. Our RTAT protocol resulted in an absolute risk reduction of $17 \%(95 \% \mathrm{CI}-2.2$ to 36.6$)$ and odds ratio $=2.0(95 \% \mathrm{CI} 0.9-4.6)$, (Table 3$)$. The majority of respiratory-related cardiothoracic ICU readmissions were attributed to acute hypercapnic (38\%) and acute hypoxemic respiratory failure $(35 \%)$. Acute hypercapnic respiratory failure was the most common primary respiratory-related reason for ICU readmission within the physician-ordered respiratory care group (38\%), whereas acute hypoxemic respiratory failure was most common reason within the RTAT group (43\%) (Table 4).

\section{Discussion}

ICU recidivism can have a significant impact on patients, caregivers, and hospital operations. Readmissions 
Table 3. Treatment Group Respiratory-Related ICU Readmission Status

\begin{tabular}{|c|c|c|c|}
\hline Respiratory Care Treatment Group & $\begin{array}{l}\text { Respiratory-Related } \\
\text { Cardiothoracic ICU } \\
\text { Readmission, } n(\%)\end{array}$ & $\begin{array}{l}\text { Cardiothoracic ICU } \\
\text { Readmission With no } \\
\text { Respiratory-Related } \\
\text { Component, } n(\%)\end{array}$ & Total, $n$ \\
\hline Physician-ordered respiratory care (control group) & $34(53)$ & $30(47)$ & 64 \\
\hline Respiratory therapy assess-and-treat protocol (experimental group) & $14(36)^{*}$ & $25(64)$ & 39 \\
\hline Total & 48 & 55 & 103 \\
\hline
\end{tabular}

Table 4. Primary Reason for Respiratory-Related Cardiothoracic ICU Readmission

\begin{tabular}{lccr}
\hline \hline \multicolumn{1}{c}{ Reasons } & $\begin{array}{c}\text { Respiratory Therapy } \\
\text { Assess-and-Treat } \\
\text { Protocol Group }(n=14)\end{array}$ & $\begin{array}{c}\text { Physician-Ordered } \\
\text { Respiratory Care } \\
\text { Group }(n=34)\end{array}$ & $13(38)$ \\
Acute hypercapnic respiratory failure & $4(31)$ & $11(32)$ & $18(38)$ \\
Acute hypoxemic respiratory failure & $6(43)$ & $10(29)$ & $17(35)$ \\
Airway secretion retention & $3(21)$ & \\
\hline Data are presented as $n(\%)$. & & & $13(27)$ \\
\hline
\end{tabular}

or unexpected ICU admissions result in less than optimal outcomes. Unexpected ICU admissions and readmissions are associated with increased length of stay, higher mortality, increased work load for bedside clinicians, and higher costs of care. ${ }^{7}$ As a result, ICU readmissions are becoming a focus of health-care organizations in the quest to improve quality and reduce costs of care. ${ }^{10}$ Nationally, academic hospitals typically experience a higher rate of ICU readmissions than non-academic settings, with the greatest percentage of ICU readmissions occurring within $3 \mathrm{~d}$ of ICU discharge. ${ }^{11}$ The reasons for increased risk of ICU readmissions are multifactorial. Age, pre-hospital conditions, surgical procedure, comorbidity, step-down bed availability, physician resident training, and case mix index have been reported as contributing factors. ${ }^{7-12}$

Our study demonstrated a statistically significant reduction in all-cause ICU readmissions or unplanned admissions with RTAT protocol compared with physician-ordered respiratory care. Despite these results, it should be understood that the most optimally applied RTAT protocol will not be able to prevent a readmission attributable to conditions not respiratory-related (eg, renal failure requiring continuous renal replacement therapy, excessive postoperative bleeding).

Previously reported work has identified respiratory sequelae as an overriding factor related to ICU readmissions. ${ }^{7,11,12}$ Targeting conditions attributable to respiratory compromise (eg, atelectasis, secretion retention) with RTAT protocols has the potential to improve causal outcomes. Our RTAT protocol reduced respiratory-related ICU readmissions but did not reach statistical significance. Our results demonstrate that registered respiratory therapists, as a part of the interdisciplinary health-care team, decreased respiratory-related adult cardiothoracic ICU readmissions when using an RTAT protocol. This supports medical center and health reform objectives that focus on interdisciplinary collaboration, patient safety, quality, and improved outcomes.

In this study, we have reported how respiratory therapist-managed protocols can be a valuable tool for physicians treating patients outside of the ICU. Previous work has demonstrated that respiratory therapist-managed protocols are effective in patient assessment, ventilator management and liberation, arterial blood gas sampling, oxygen titration, and other interventions both inside and outside the ICU.1-6 Our study takes important steps toward identifying the impact of RTAT protocols on the adult postoperative cardiothoracic population. These patients often have unresolved pain issues, fluid management challenges, diminished respiratory reserve, and other complications that can affect the continued recovery process outside the ICU. ${ }^{13}$ Close attention to the respiratory-related needs of this population can reduce readmissions to the ICU. ${ }^{14}$ To this end, respiratory therapists have been identified as important to improving patient outcomes outside the ICU. ${ }^{15}$ Further studies should be conducted to determine whether respiratory therapist-managed assess-and-treat protocols might reduce ICU readmissions in other patient populations.

The RTAT protocol has provided additional benefits beyond reducing readmissions. The RTAT clinical assessor serves as an additional resource in the acute care and thoracic intermediate care unit wards for interdisciplinary care planning and complex case management. Cardiothoracic ICUs are frequently challenged to improve patient flow and create 
bed availability for postoperative patients. The RTAT protocol contributes to efficient patient flow by helping to reduce unexpected use of ICU beds reserved for postoperative patients. For these reasons, the RTAT protocol has been well received by all disciplines and senior hospital leadership.

Our project has the following limitations. Retrospective studies typically do not include the randomized assignment of subjects between treatment groups. Therefore, control of confounding variables and the identification of causal relationships can be problematic. This is exemplified in our study by an unequal distribution of case mix index between the control and study groups. We had anticipated a closer match on case mix index between the control and study period. Surgical populations varied between most groups, notably heart transplant/left-ventricular assist device, valve, aortic/vascular, lung/chest, and esophagectomy. Additionally, preference for respiratory care orders may have varied among physicians relative to the control group, whereas the RTAT protocol was standardized.

Although we report a difference in ICU readmissions between groups, respiratory-related readmissions was statistically underpowered. A post hoc power analysis indicates that our study was insufficiently powered to accept or reject the secondary hypothesis. Using a power of 0.8 , respiratory-related ICU readmissions would have required 133 subjects/group to reach statistical power to avoid a type-2 error. The 17\% absolute risk reduction we observed in RTAT respiratory-related ICU readmissions suggests a positive clinical impact despite not reaching statistical significance.

The clinical assessor was not blinded to readmission cause, and physician discharge practice was not controlled in this study. ICU bed demands may have resulted in the early discharge of borderline subjects to the acute care/thoracic intermediate care units. It is unknown what effect this may have had on outcomes. Finally, the patient population was limited to adult postoperative cardiothoracic subjects, making it difficult to generalize these results to other patient populations. However, the results of our study were encouraging enough to suggest that variations of this approach could have similar impacts elsewhere.

\section{Conclusions}

We reject the null hypothesis that there is no difference in all-cause cardiothoracic readmissions in the compared groups. Because of insufficient sample size, we are unable to accept or reject the secondary null hypothesis that there is no difference in primary respiratory-related ICU readmissions, ICU stay, and hospital stay. A larger, prospec- tive randomized controlled trial is necessary to provide a higher level of evidence on these outcomes and their application to a broader patient population.

\section{REFERENCES}

1. Kollef MH, Shapiro SD, Clinkscale D, Cracchiolo L, Clayton D, Wilner R, Hossin L. The effect of respiratory therapist-initiated protocols on patient outcomes and resource utilization. Chest 2000; 117(2):467-475.

2. Colice GL, Carnathan B, Sung J, Paramore LC. A respiratory therapistdirected protocol for managing inpatients with asthma and COPD incorporating a long-acting bronchodilator. J Asthma 2005;42(1):29-34.

3. Harbrecht BG, Delgado E, Tuttle RP, Cohen-Melamed MH, Saul MI, Valenta CA. Improved outcomes with routine respiratory therapist evaluation of non-intensive-care-unit surgery patients. Respir Care 2009;54(7):861-867.

4. Modrykamien AM, Stoller JK. The scientific basis for protocoldirected respiratory care. Respir Care 2013;58(10):1662-1668.

5. Stoller J. The effectiveness of respiratory care protocols. Respir Care 2004;49(7):761-765.

6. Marelich GP, Murin S, Battistella F, Inciardi J, Vierra T, Roby M. Protocol weaning of mechanical ventilation in medical and surgical patients by respiratory care practitioners and nurses: effect on weaning time and incidence of ventilator-associated pneumonia. Chest 2000;118(2):459-467.

7. van Diepen S, Graham MM, Nagendran J, Norris CM. Predicting cardiovascular intensive care unit readmission after cardiac surgery: derivation and validation of the Alberta Provincial Project for Outcomes Assessment in Coronary Heart Disease (APPROACH) cardiovascular intensive care unit clinical prediction model from a registry cohort of 10,799 surgical cases. Critical Care 2014;18(6):651-659.

8. Kramer AA, Higgins TL, Zimmerman JE. The association between ICU readmission rate and patient outcomes. Crit Care Med 2013; 41(1):24-33.

9. Magruder JT, Kashiouris M, Grimm JC, Duquaine D, McGuinness $\mathrm{B}$, Russell S, et al. A predictive model and risk score for unplanned cardiac surgery intensive care unit readmissions J Card Surg 2015; 30(9):685-690.

10. Al-Jaghbeer MJ, Tekwani SS, Gunn SR, Kahn JM. Incidence and etiology of potentially preventable ICU readmissions. Crit Care Med 2016;44(9):1704-1709.

11. Brown SE, Ratcliffe SJ, Kahn JM, Halpern SD. The epidemiology of intensive care unit readmissions in the United States. Am J Respir Crit Care Med 2012;185(9):955-964.

12. Vohra HA, Goldsmith IR, Rosin MD, Briffa NP, Patel RL. The predictors and outcomes of recidivism in cardiac ICUs. Eur J Cardiothorac Surg 2005;27(3):508-511.

13. Kogan A, Cohen J, Raanani E, Sahar G, Orlov B, Singer P, Vidne B. Readmissions to the intensive care unit after "fast-track" cardiac surgery: risk factors and outcomes. Ann Thorac Surg 2003;76(2):503-507.

14. Nishi GK, Suh RH, Wilson MT, Cunneen SA, Margulies DR, Shabot MM. Analysis of causes and prevention of early readmission to surgical intensive care. American Surg 2003;69(10):913-917.

15. Rosenberg AL, Watts C. Patients readmitted to ICUs: A systematic review of risk factors and outcomes. Chest 2000;118(2):492-502.

This article is approved for Continuing Respiratory Care Education credit. For information and to obtain your CRCE

(free to AARC members) visit www.rcjournal.com

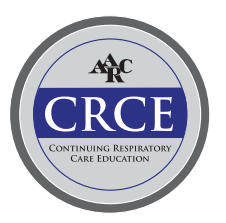

